Proc. of the X Int. Conf. - Ion Implantation and other Applications of Ions and Electrons, Kazimierz Dolny 2014

\title{
Research on Thermal Stability of Electrical Parameters of Silicon Used in PV Cells Production Process
}

\author{
P. WEGIEREK* AND P. BILlEWICZ \\ Lublin University of Technology, Nadbystrzycka 38A, 20-618 Lublin, Poland
}

\begin{abstract}
Considering the results of recent research, it is possible to state that the problem of thermal stability of electrical parameters of silicon is very important in the context of efficiency of commonly used photovoltaic cells. Subsequent investigations confirmed that the efficiency of photovoltaic cells is strongly influenced by active defects of silicon crystal lattice. Those defects, arising in the process of photovoltaic cells base material preparation, are responsible for changes in the values of conductivity and activation energy of the tested material. Taking this into consideration, it is reasonable to carry out research oriented at experimental verification of the influence of both operating temperature on the electrical parameters of silicon and annealing temperature on the distribution of radiation defects in the silicon substrate used in the production of photovoltaic cells. The main purpose of this work is a comparative analysis of dependences of electrical parameters of silicon on temperature. The article presents the results of the research on resistivity and capacity of silicon samples (doped with boron and phosphorus) whose structure was modified by the ion implantation process.
\end{abstract}

DOI: $10.12693 /$ APhysPolA.128.943

PACS: 61.72.uj, 61.72.Cc, 72.80.Ey

\section{Introduction}

The problem of modifying properties of semiconductor materials, which are basically used in the process of photovoltaic (PV) modules production, in order to provide maximum efficiency of solar cells has been the subject of discussion in many scientific publications and investigations [1-6]. Summarizing the results of performed experiments, the authors emphasized significant influence of temperature on the crucial operating parameters of solar cells. In addition, the research described in [7] showed that the efficiency of PV cells substantially depends on the level of solar radiation and resistance of the substrate material of which the cell is constructed. Simultaneously, in $[7,8]$, it was confirmed that along with the increase of the operating temperature of a PV cell, it is possible to observe a significant decrease in the values of indicators determining the quality of the considered PV cell such as open-circuit voltage, maximum power, fill factor and efficiency.

Considering the process of solar energy conversion into electricity in terms of the number of generated electric charge carriers, it is noticeable that the character of phenomena observed by the authors of $[1-8]$ is strongly connected with electrical properties of the substrate material of PV cell and the form of its internal structure. Additionally, the paper [8] presents the results of the research which indicate that, among common materials used for production of PV cells, monocrystalline silicon has the highest maximum conversion efficiency. Furthermore, in Ref. [6] it was emphasized that the charge carrier lifetime $\tau$ distribution and the length of diffusion in

${ }^{*}$ corresponding author; e-mail: p.wegierek@pollub.pl the silicon structure $L_{\mathrm{D}}$ are important from the point of view of photoconversion efficiency. The authors of the monograph showed that the efficiency of PV cells is strongly influenced by active defects in silicon crystal lattice. Those defects, arising in the process of PV cells base material preparation, are responsible for changes in the conductivity and activation energy of the tested material. Moreover, it was underlined that it is possible to control the process of radiation defects formation during ion implantation of silicon.

Taking into consideration the results of the research presented above, it could be concluded that solving the problem of thermal stability of electrical properties of silicon is essential to ensure higher efficiency of commonly used solar cells. Therefore, it is reasonable to conduct research directed at experimental verification of the influence of operating temperature on the electrical parameters of silicon as well as that of annealing temperature on the distribution of radiation defects in silicon substrates used in the production of PV cells.

\section{Experiment}

The main purpose of the performed experiment was to determine optimal implantation and post-implantation treatment conditions in order to achieve maximum stability of the measured values of resistivity $\rho$ and capacity $C$ in the function of the operating temperature $T_{\mathrm{p}}$ and annealing temperature $T_{\mathrm{a}}$. As the object of research, six samples of silicon have been chosen. Samples number 1, 3 and 5 were silicon doped with boron of the resistivity $\rho=0.07,10$, and $0.01 \Omega \mathrm{cm}$, respectively. Samples number 2 and 4 were the silicon doped with phosphorus of the resistivity $\rho=0.25 \Omega \mathrm{cm}$ and $10 \Omega \mathrm{cm}$, respectively. Sample number 6 was the silicon doped with antimony of the resistivity $\rho=0.01 \Omega \mathrm{cm}$. The tested samples were subjected to implantation of $\mathrm{Ne}^{+}$ions of energy 
$E=100 \mathrm{keV}$ and fluence $D=2.2 \times 10^{14} \mathrm{~cm}^{-2}$ (samples 1 and 2) and $1.5 \times 10^{14} \mathrm{~cm}^{-2}$ (samples $\left.3-6\right)$. The measurements were performed in the operating temperature range from $173 \mathrm{~K}$ to $373 \mathrm{~K}$. During the experiment the samples were isochronously annealed for $15 \mathrm{~min}$, within the range of annealing temperatures $T_{\mathrm{a}}$ up to $873 \mathrm{~K}$, with the average increments of $(30 \div 50) \mathrm{K}$. The initial sample parameters as well as implantation conditions and annealing temperature were determined on the basis of previously carried out research, described in $[9,10]$.

\section{Analysis of the obtained results}

In the first stage of recorded results analysis, the temperature dependence of resistivity was plotted for all tested samples in the unannealed state (Fig. 1). On this basis it was possible to specify which samples have the best thermal stability of resistivity rate directly after ion implantation. In Fig. 1 it can be seen that samples 5 and 6 are characterized by the least amplitude of resistivity values fluctuations within the temperature range $(170 \div 300) \mathrm{K}$. Moreover, resistivity recorded for sample 3 also varies within one order of magnitude. For that reason those samples were chosen for further analysis, however, subsequent dependences refer to samples 3 and 5 in order to eliminate influence of the kind of dopant.

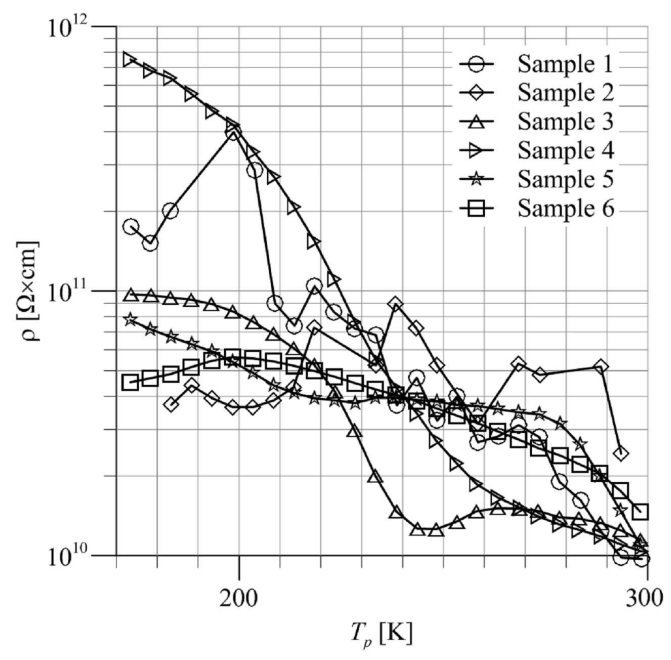

Fig. 1. Dependences $\rho=f\left(T_{\mathrm{p}}\right)$ for the unannealed samples of Si with different types of doping, resistivity and fluence values, implanted with $100 \mathrm{keV} \mathrm{Ne}{ }^{+}$ions.

The second stage of analysis covered determination of the degree of influence of annealing temperature on stability of resistivity and capacity values of chosen samples. For sample 3 (Fig. 2), which was boron-doped silicon of $\rho=10 \Omega \mathrm{cm}$, it can be seen that an increase in the testing temperature $T_{\mathrm{p}}$ causes different changes in the $\rho$ values, depending on the annealing temperature. In particular, for the annealing temperatures $423,523,623$, and $723 \mathrm{~K}$ resistivity ranges from $10^{11} \Omega \mathrm{cm}$ to $10^{14} \Omega \mathrm{cm}$ and is reduced by two to five orders of magnitude, respectively, with the increase in $T_{\mathrm{p}}$. However, it is noticeable that

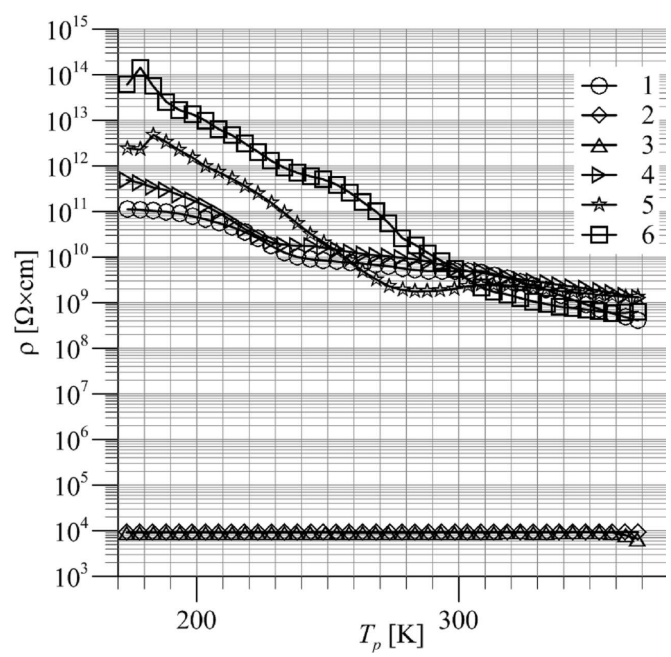

Fig. 2. Dependences $\rho=f\left(T_{\mathrm{p}}\right)$ for the sample of Bdoped Si of $\rho=10 \Omega \mathrm{cm}, 100 \mathrm{keV} \mathrm{Ne}{ }^{+}$ion-implanted with the fluence $D=1.5 \times 10^{14} \mathrm{~cm}^{-2}$, annealed at different temperatures $T_{\mathrm{a}}: 1-423 \mathrm{~K}, 2-448 \mathrm{~K}, 3-473 \mathrm{~K}$, $4-523 \mathrm{~K}, 5-623 \mathrm{~K}, 6-723 \mathrm{~K}$.

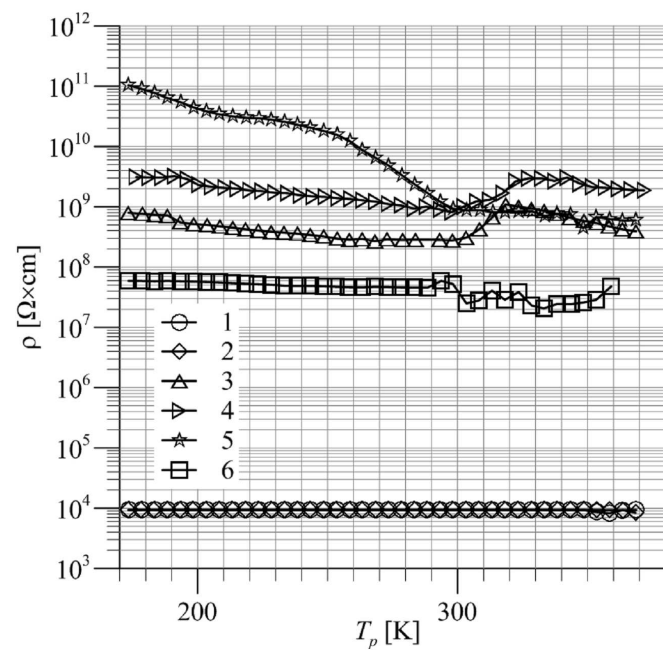

Fig. 3. As in Fig. 2, but for $\rho=0.01 \Omega \mathrm{cm}$, annealed at different temperatures $T_{\mathrm{a}}: 1-423 \mathrm{~K}, 2-448 \mathrm{~K}$, $3-473 \mathrm{~K}, 4-548 \mathrm{~K}, 5-598 \mathrm{~K}, 6-823 \mathrm{~K}$.

for $T_{\mathrm{a}}$ the values of $448 \mathrm{~K}$ and $473 \mathrm{~K}$ sample resistivity is actually not influenced by testing temperature in the whole considered $T_{\mathrm{p}}$ range. It also needs to be emphasized that $\rho$ values recorded for those two cases are much lower than for the rest of plots and equal $10^{4} \Omega \mathrm{cm}$. This leads to the conclusion that ion implantation caused a significant increase in the value of tested sample resistivity from $10 \Omega \mathrm{cm}$ before implantation to $\left(10^{10} \div 10^{11}\right) \Omega \mathrm{cm}$ directly after implantation, whereas post-implantation annealing at $448 \mathrm{~K}$ and $473 \mathrm{~K}$ reduced it substantially by seven orders of magnitude and ensured its thermal stability under different operating conditions. A similar tendency can be observed for sample 5, which was boron-doped silicon of $\rho=0.01 \Omega \mathrm{cm}$ (Fig. 3). As it can be seen, annealing the implanted sample at $423 \mathrm{~K}$ 


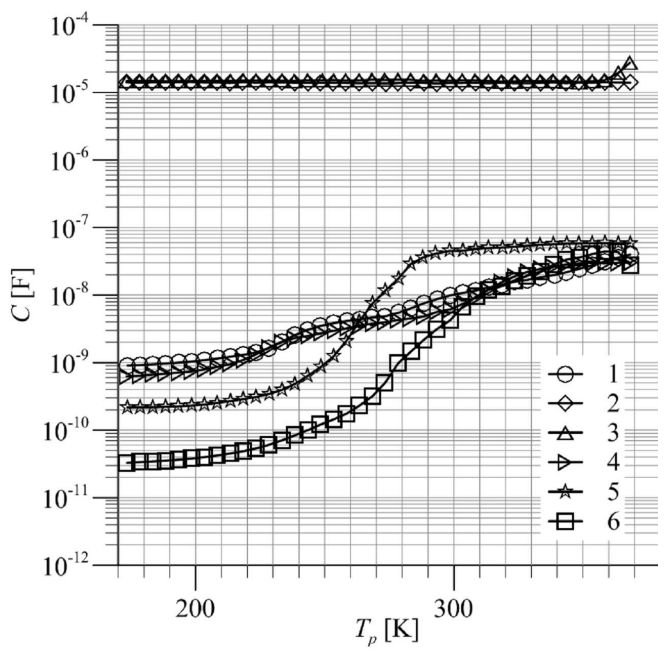

Fig. 4. Dependences $C=f\left(T_{\mathrm{p}}\right)$ for the sample of Bdoped $\mathrm{Si}$ of $\rho=10 \Omega \mathrm{cm}, 100 \mathrm{keV} \mathrm{Ne}{ }^{+}$ion-implanted with the fluence $D=1.5 \times 10^{14} \mathrm{~cm}^{-2}$, annealed at different temperatures $T_{\mathrm{a}}: 1-423 \mathrm{~K}, 2-448 \mathrm{~K}, 3-473 \mathrm{~K}$, $4-523 \mathrm{~K}, 5-623 \mathrm{~K}, 6-723 \mathrm{~K}$.

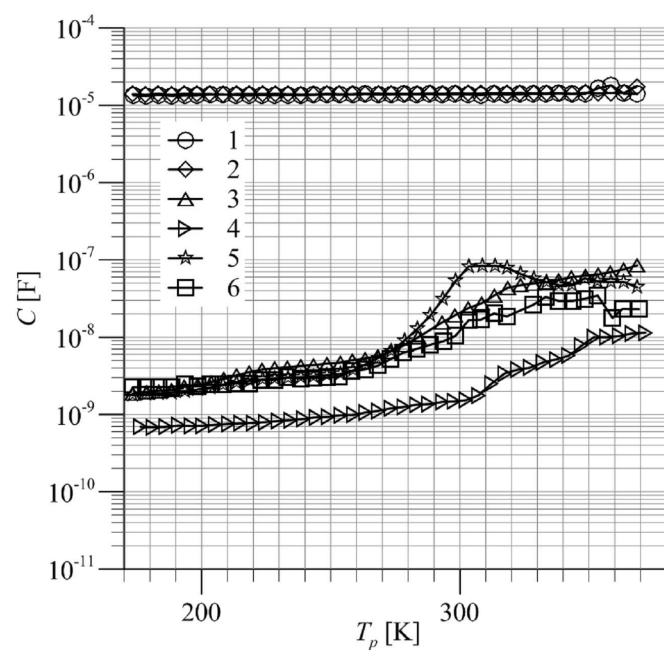

Fig. 5. As in Fig. 4, but for $\rho=0.01 \Omega \mathrm{cm}$, annealed at different temperatures $T_{\mathrm{a}}: 1-423 \mathrm{~K}, 2-448 \mathrm{~K}$, $3-473 \mathrm{~K}, 4-548 \mathrm{~K}, 5-598 \mathrm{~K}, 6-823 \mathrm{~K}$.

and $448 \mathrm{~K}$ eliminates the influence of operating temperature on resistivity and stabilizes its value at the same level of $10^{4} \Omega \mathrm{cm}$, whereas annealing at higher temperatures up to $823 \mathrm{~K}$ does not induce such tendency.

Considering capacity dependences on the testing temperature $T_{\mathrm{p}}$ for samples 3 and 5 , it is possible to observe that the recorded plots consequently confirm thermal stability after annealing at $T_{\mathrm{a}}$ (Figs. 4,5 ). For sample 3 capacity stabilizes at the level of $10^{-5} \mathrm{~F}$ when annealed at $448 \mathrm{~K}$ and $473 \mathrm{~K}$, whereas for sample 5 the same situation occurs at $423 \mathrm{~K}$ and $448 \mathrm{~K}$.

\section{Conclusions}

Comparative analysis of the temperature dependences presented above, plotted for the ion-implanted silicon samples, was aimed at evaluating ion implantation conditions as well as the implanted sample parameters in the way that ensures high thermal stability rate in the considered range of operating temperatures $T_{\mathrm{p}}$. As a result, it was concluded that in silicon doped with boron, defected by the process of ion implantation and annealed in the temperature range $423 \div 473 \mathrm{~K}$ thermal stability of resistivity and capacity was observed. This proves that it is possible to choose such parameters of ion implantation and post-implantation processes that will allow to produce silicon material whose electric parameters are stable at the predetermined level under the changing thermal conditions. The experiments performed and described in our previous papers were focused on optimizing implantation parameters in order to obtain high resistivity regions in silicon substrates which could be applied in the process of integrated circuits vertical isolation production. However, this paper begins a new cycle of research whose main purpose is to find such silicon sample configuration and implantation parameters that will allow to produce low-resistivity, monocrystalline silicon substrate characterized by significantly high thermal stability of resistivity. Outcomes of the started research could be used in the photovoltaic cells production industry, resulting in introducing improved PV modules whose operating parameters, e.g. nominal power or efficiency, are not affected by the outside temperature.

\section{References}

[1] S.J. Fonash, Solar Cell Device Physics, Academic Press, Burlington 1981.

[2] A. Goetzberger, J. Knobloch, V. Bernhard, Crystalline Silicon Solar Cells, Wiley, Chichester 1998.

[3] NATO Science Series. Photovoltaic and Photoactive Materials - Properties, Technology and Applications, Eds. J.M. Marshall, D. Dimova-Malinovska, Kluwer Academic, Sozopol 2002.

[4] Handbook of Photovoltaic Science and Engineering, Eds. A. Luque, S. Hegedus, Wiley, Chichester 2011.

[5] M. Fehr, P. Simon, T. Sontheimer, C. Leendertz, B. Gorka, A. Schnegg, B. Rech, K. Lips, Appl. Phys. Lett. 101, 123904 (2012).

[6] N. Drozdov, A. Fedotov, A. Mazanik, J. Partyka, P. Węgierek, P. Żukowski, Photovoltaic Cells for Solar Energetics - Materials Engineering Aspects, Lublin University of Technology Academic Publishing, Lublin 2006.

[7] V. Benda, Z. Macháček, in: IET Conf. Publications, rth Mediterranean Conf. and Exhibition on Power Generation, Transmission, Distribution and Energy Conversion, MedPower, IET, Agia Napa 2010, p. 163.

[8] V. Benda, AIP Conf. Proc. 1499, 6 (2012).

[9] P. Żukowski, J. Partyka, P. Węgierek, Phys. Status Solidi A 159, 509 (1997).

[10] J. Partyka, P. Żukowski, P. Węgierek, A. Rodzik, Y. Sidorenko, Y. Szostak, Semiconductors 36, 1326 (2002). 